All letters are subject to editing and may be shortened. Letters should be sent to the BJGP office by e-mail in the first instance, addressed to

journal@rcgp.org.uk (please include your postal address). Alternatively, they may be sent by post as an MS Word or plain text version on CD or DVD. We

regret that we cannot notify authors regarding publication. Letters not published in the Journal may be posted online on our Discussion Forum. For instructions please visit: http://www.rcgp.org.uk/bjgp-discuss

\section{Complementary and alternative medicine}

It is regrettable that the BJGP should publish obviously wrong medical information. In his paper, ${ }^{1}$ Professor Ernst states that a number of alternative treatments are as effective as conventional options. Presumably, Professor Ernst considers his view to be so well accepted and generally held to be true, that he provides no references to support his statements. There are examples below that clearly show that he is wrong.

He states that saw palmetto used for treatment of benign prostatic hyperplasia has similar effectiveness to conventional options. It is not stated if he means conventional medical treatments or conventional surgical treatments or both.

A 2002 Cochrane review of saw palmetto concluded that it may be better than placebo and of similar effectiveness to 5- $\alpha$ reductase inhibitors. ${ }^{2}$ In a recent high quality randomised controlled trial it was shown to be no more effective than placebo. ${ }^{3}$ To my knowledge, saw palmetto has not been studied in a head-to-head trial with $\alpha$-blocker and therefore it cannot be assumed that it is of similar effectiveness. Regarding surgical treatment, I am not aware of any randomised controlled trial comparing saw palmetto to surgical treatments or sham operation. So, his statement is untrue whichever conventional options he means.

$\mathrm{He}$ also states that treatment of depression with St John's wort has similar effectiveness to conventional treatment. Untrue. In a well-conducted randomised controlled trial in patients with major depression, St John's wort was found to have effectiveness similar to placebo. ${ }^{4}$ To my knowledge it has not been tested against most medical treatments for depression, nor against cognitive-behaviour therapy. Certainly, it has never been tested against electro-convulsive treatment, by far the most effective of all conventional treatments for severe depression.

He states that hawthorn for treatment of heart failure has the same effectiveness as conventional options. Let us remind the readers about some conventional options. ${ }^{5}$ The proven ones include: diuretics, $\beta$ blockers, ACE inhibitors, nitrates, digoxin, bi-ventricular pacing, ventricular assist devices, and heart transplant. His statement seems so outlandish that I feel I need not provide any further references.

Presumably the article ${ }^{1}$ was peerreviewed and approved by the Editor for publication. They singularly have failed in their duties on this occasion.

\section{Nick Manassiev}

GP, 1 Goodrest Croft, Birmingham, B14 4JU.

E-mail:d_manassieva@hotmail.com

\section{REFERENCES}

1. Ernst E. Complementary and alternative medicine: what the NHS should be funding? Br J Gen Pract 2008; 58(548): 208-209.

2. Wilt T, Ishani A, MacDonald R. Serenoa repens for benign prostatic hyperplasia. Cochrane Database Syst Rev 2002; 3: CD001423.

3. Bent S, Kane C, Shinohara K, et al. Saw palmetto for benign prostatic hyperplasia. N Engl J Med 2006; 354: 557-566.

4. Shelton RC, Keller MB, Gelenberg A, et al. Effectiveness of St John's wort in major depression: a randomized controlled trial. JAMA 2001; 285: 1978-1986.

5. Nohria A, Lewis E, Stevenson LW. Medical management of advanced heart failure. JAMA 2002; 287: 628-640.

DOI: 10.3399/bjgp08X280227

\section{Re: Complementary and alternative medicine}

The original article was not peer-reviewed, but was approved by the Deputy Editor. We've become aware that this may not be clear, and have recently decided to follow the BMJ's example and publish details for each paper so that readers are not left in any doubt - Ed.

DOI: 10.3399/bjgp08X280236

\section{Author's response}

Dr Nick Manassiev accuses me of putting out 'wrong medical information'. He claims that I provide no references. However, my text is quite clear that the information is my attempt to summarise the evidence reviewed in our two books. ${ }^{1,2}$ In other words, all the necessary references can be found there because constraints of space would not have allowed me to proceed in any other way.

Is saw palmetto equivalent to conventional drug treatment? (Yes, I did mean to compare only oral treatments.) Even though the data are not entirely uniform (they rarely are), the Cochrane review concluded that it produced similar improvements in urinary symptoms and flow as finasteride and is associated with fewer adverse events. ${ }^{3}$

St John's wort has been tested in more than 30 well-conducted randomised controlled trials. Again, the results are not entirely uniform but collectively the data are positive. In five randomised controlled trials (total sample size $=2251$ ), St John's wort was tested against conventional antidepressants and the meta-analytic risk ratio was $0.96(95 \% \mathrm{Cl}=0.85$ to 1.08$) .^{4}$

Hawthorn is backed up by a positive Cochrane review of 14 randomised controlled trials, ${ }^{5}$ and a recent randomised controlled trial with 2681 patients showed that, during 18 months of hawthorn treatment, deaths due to cardiac causes were reduced by $20 \%$ compared to placebo. ${ }^{6}$

In my article, I do acknowledge that comparing one (complementary) with another (conventional) treatment is by no means straight forward. In fact, I state that: 'This is where things change from complicated to nebulous.' But I do nevertheless insist that the information I provided is based on the best available evidence. $^{1,2}$ 